\title{
Text Messaging in the Patient-Centered Medical Home to Improve Glucose Control and Retinopathy Screening
}

\author{
Janice M. Miller,, ${ }^{1, *}$ Ann G. Phalen, Albert Crawford, ${ }^{2}$ Anthony Frisby, ${ }^{3}$ and Barry S. Ziring ${ }^{4}$
}

\begin{abstract}
Purpose: To evaluate the effectiveness of a text messaging program (TMP) to improve glucose control, retinopathy screening (RS) rates, and self-care behaviors in patients with uncontrolled type 2 diabetes.

Methods: A single-group design with a quasi-systematic random sample $(n=20)$ received educational/exhortational text messages on their cellular phones for 3 months. Subjects, 12 of whom identified as a minority ethnicity, were mostly male, aged 27-73 years.

Results: Glucose control and RS rates improved significantly. Subjects ( $>70 \%)$ reported changes in self-care behaviors.

Conclusion: Leveraging ubiquitous technology, a TMP for patients with limited access to healthcare education, holds promise.
\end{abstract}

Keywords: diabetes; diabetes education; text messaging; patient-centered medical home; retinopathy screening; self-care

\section{Introduction}

Equity, accessibility, safety, efficiency, timeliness, patient centeredness, and effectiveness are domains identified by the Institute of Medicine (IOM) to define high-quality healthcare. Minority patients and those of low socioeconomic status have difficulty accessing or navigating the health system and thus receive lower quality care. ${ }^{1}$ Type 2 diabetes (T2DM) is a complex disease whose poor control portends life altering, costly complications. T2DM impacts minority populations more frequently than Caucasians. ${ }^{2}$ Preventive screenings and blood glucose control decrease complications or identify them early. Approximately 59\% of patients have retinopathy screening (RS) to identify early changes leading to blindness, and 36\% have controlled T2DM. ${ }^{3}$ Glucose control is measured using the hemoglobin A1C test (A1C), which measures glucose control over a 3 -month period. The tar- get for most patients is $\leq 7 \mathrm{mg} / \mathrm{dL}^{4}{ }^{4}$ Without ongoing education and support, patients often fall short of goals.

Following the example of large-scale public health initiatives, a text messaging program (TMP) for patients with T2DM has the potential to impact patients in short segments. ${ }^{5}$ Leveraging cell phone technology that is ubiquitous in the population affords the opportunity to integrate education in a manner that is equitable, accessible, portable, and efficient. This pilot study evaluated the effectiveness of a TMP in 20 subjects with uncontrolled $\mathrm{T} 2 \mathrm{DM}$ to improve $\mathrm{A} 1 \mathrm{C}$, RS rates, and performance of the American Association of Diabetes Educators (AADE) self-care behaviors. ${ }^{6}$ Referred to as Mobile Health, this methodology uses "push" technology, transmitting information without the user initiating the request. ${ }^{7}$ TMPs have demonstrated effectiveness in appointment keeping, vaccine reminders,

\footnotetext{
'Jefferson College of Nursing, Thomas Jefferson University, Philadelphia, Pennsylvania.

${ }^{2}$ College of Population Health, Thomas Jefferson University, Philadelphia, Pennsylvania.

${ }^{3}$ Center for Teaching and Learning, Thomas Jefferson University, Philadelphia, Pennsylvania.

${ }^{4}$ Department of Medicine, Sidney Kimmel Medical College at Thomas Jefferson University, Philadelphia, Pennsylvania. 
breastfeeding, weight loss, physical activity improvement, improving nutritional intake, HIV testing, and to support decision-making for parents of critically ill neonates. ${ }^{8-15}$

\section{Methods}

All study procedures were approved by the University's Institutional Review Board. This study utilized a preand postsingle-group intervention design in an urban, academic Internal Medicine practice designated as a Level III patient-centered medical home (PCMH) by the National Committee on Quality Assurance (NCQA). Practice data revealed that $55 \%$ of patients with diabetes had RS within the last year, a metric close to national averages, but that had not improved despite practice efforts. Quality metrics for glucose control within the practice were similar to national averages of $36 \%$. Adult subjects were eligible to participate if they had T2DM, a most recent A1C reading $>7.5$ within the prior 3 months, were English speaking, had no cognitive dysfunction, no anemia, and were able to read text messages on their cell phone. A quasisystematic random sampling methodology was utilized to include patients who had a scheduled appointment with one of each of the 12 full-time providers in the practice. This prevented oversampling of a few providers to better represent the practice's T2DM population. All subjects were recruited over 10 weeks. Informed consent was obtained. Subjects texted the keyword "Diabetes" from their cell phone to an investigator contracted short message service vendor. This anonymously enrolled them in the distribution list. Subjects received an immediate response message welcoming them to the program and confirming their enrollment. Subjects were given the book entitled "Living with Diabetes," which contains comprehensive selfmanagement information and color pictures. ${ }^{16}$ Medications, A1C readings, and most recent RS dates were extracted from the subjects' Electronic Medical Record (EMR). The categorizations of RS (up to date or not up to date) were defined as a consultation letter of a dilated ophthalmologic examination in the patient's EMR within 12 months before study enrollment.

\section{Interventions}

Subjects received text messages three times throughout the week for 12 consecutive weeks. All enrolled participants received the same message on the same day at the same time. All subjects received the same 36 messages.
Messages were limited by the investigator contracted vendor to 160 characters. The targets of all messages were to improve $\mathrm{A} 1 \mathrm{C}$ and $\mathrm{RS}$ rates. Information was stated in simple language to be understood by participants with low health literacy. Messages contained phone numbers to procure ophthalmology appointments and tips in self-care formulated from information or standards designated by the American Diabetes Association (ADA) or AADE. Each of the AADE behaviors was addressed in the message content. Numerous messages integrated more than one self-care behavior. Due to heterogeneity of subjects and variety of medications prescribed, messages pertaining to medications were generalized and exhortative. At completion, subjects completed a five-point Likert scale survey of their impressions of the TMP and questions reflecting the self-care behaviors of the AADE.

\section{Results}

Population characteristics

Subject demographics and baseline characteristics are listed in Table 1. A wide range of subject ages and ethnicities participated. Although relatively equal numbers of men and women were approached for participation, male subjects outnumbered female 3:1. One subject was legally blind due to sarcoidosis, but an application on his cell phone converted text to voice messaging and facilitated his ability to send and receive information. While no subjects actively withdrew from the study, six subjects did not keep follow-up appointments or return the exit survey that was then mailed to them.

Twelve subjects (60\%) completed all pre- and postintervention surveys and laboratory work. Fourteen

Table 1. Subject Demographics $(n=20)$

\begin{tabular}{lc}
\hline Male & 15 \\
Female & 5 \\
Mean age & 51.8 \\
Age range & $27-73$ \\
Ethnicity & \\
$\quad$ African American & 9 \\
Caucasian & 7 \\
Asian & 2 \\
Hispanic & 1 \\
Other & 1 \\
Years since diagnosis & 11.3 \\
Mean baseline A1C & $9.4 \%$ \\
Range of baseline A1C & $7.5-14.2 \%$ \\
Family history of diabetes, $n$ & 15 unknown/adopted $=1$ \\
Using insulin, $n$ & 11 \\
Prior diabetes education, $n$ & 13 \\
\hline
\end{tabular}


subjects (70\%) completed exit surveys. Paired $t$-tests were performed for pre- and post-A1C readings. Fisher's exact test was utilized to evaluate categorical data of RS. Statistical analysis utilized SAS version 9.2 software.

\section{Glucose control}

Eleven of 14 participants had paired data and demonstrated reductions in $\mathrm{AlC}$. The range of $\mathrm{AlC}$ change was from -3.4 to +1.1 . Paired $t$-tests of pre- and postintervention A1C $(n=14)$ revealed an overall mean reduction of 0.83 , from 9.46 to $8.63 \mathrm{mg} / \mathrm{dL}(p=0.033)$.

Several factors likely impacted A1C results. A 3month time limitation may have been too soon to see improvement in A1C. Missing test results in a small sample size diminish the external validity of the study. Insulin initiation/intensification in four subjects was likely to have reduced their A1C measurements more substantially than did the concurrent TMP. Yet, $71 \%$ of patients reported increased medication adherence, a pivotal component of glucose control. An $\mathrm{A} 1 \mathrm{C}$ reduction of 0.83 in 11 participants is not to be discounted. A one-point reduction of $\mathrm{A} 1 \mathrm{C}$ reduces the likelihood of long-term complications by $35 \%{ }^{4}$ Pharmacologic agents report a similar degree of A1C reduction after initiation of therapy. A multisession diabetes education program demonstrated a similar degree of reduction to the results from this brief TMP. ${ }^{17}$

\section{Retinopathy screening}

At baseline, six subjects (30\%) were considered up to date with RS. At study completion, 11 participants

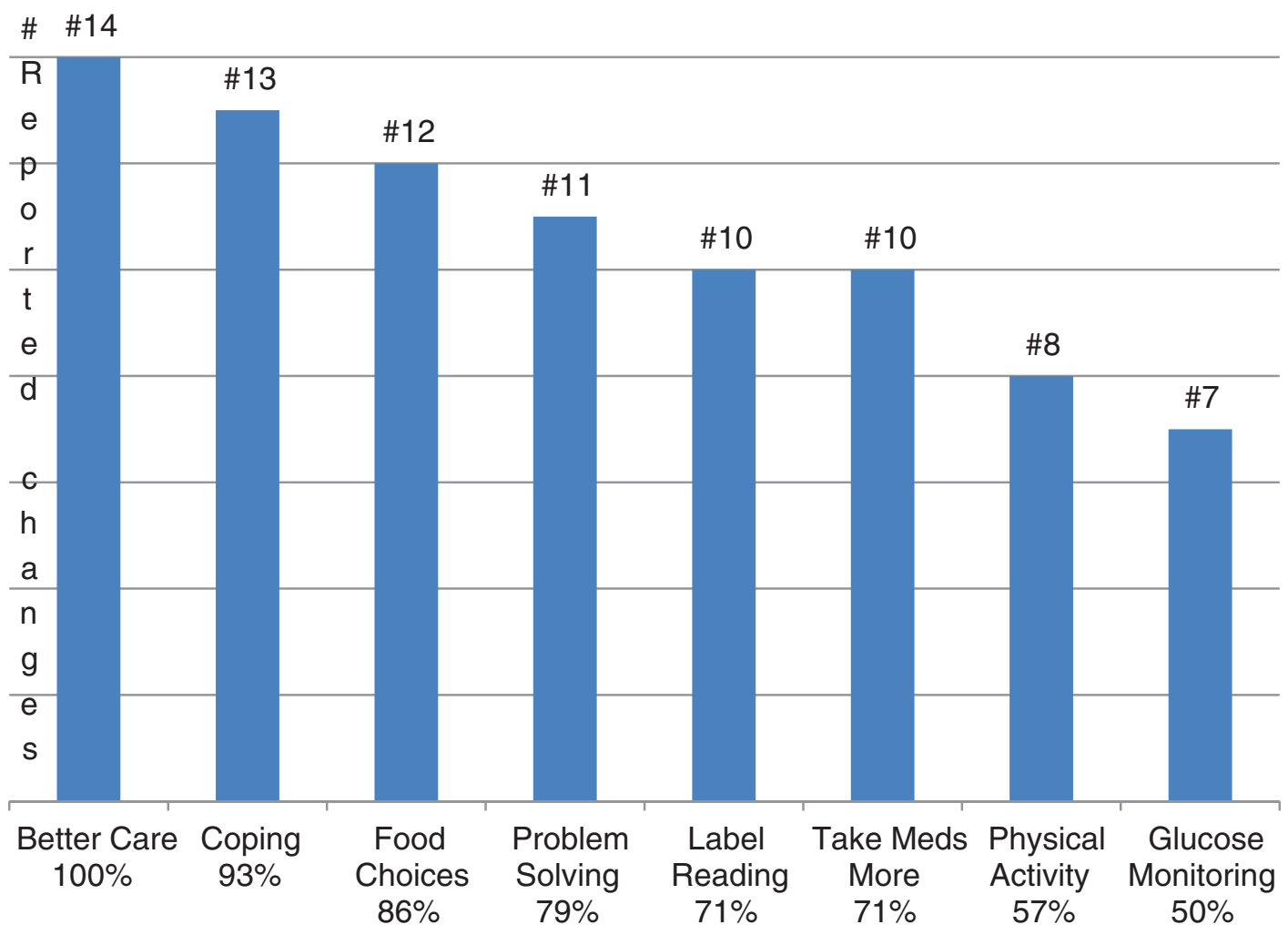

FIG. 1. Subject reported self-care behavior improvements. Numbers and percentages of subjects who agreed or strongly agreed that they had made behavior changes by category after the text messaging program: take better care of their diabetes, improved coping skills, made changes to food choices, improved problem solving, increased label reading, taking medications as prescribed, increased physical activity, and self-monitoring blood glucose. 
(55\%) were up to date $(p=0.014)$. Eight subjects (42\%) underwent RS during or shortly after the 3 months of the TMP (several who were up to date at study initiation repeated RS).

Fourteen patients were due for RS; five of whom completed RS (36\%). The subject group as a whole matched the practice's customary annual RS rate in one-fourth of the time. Perhaps more subjects had screening, but a consultation letter was not sent or scanned into the EMR.

Two confounding variables likely impacted RS rates. The practice location installed a retinal camera 1 month before study initiation; one participant had screening performed with this device. Second, as part of a national study, an ophthalmological institution offered free, impromptu RS in the lobby of the practice's building; three participants had consultation reports from this initiative. The variables, while confounding, removed barriers and facilitated performance of RS in the presence of increased cues for four of the participants. National discussion about changing health behaviors focuses on strategies that make healthy choices easier for the population. Facilitating risk reduction behaviors in the presence of TMP cues may be an optimal strategy.

\section{Exit surveys and AADE behavior changes}

All 14 subjects who completed the exit survey agreed they would recommend the TMP and that it made them want to take better care of their diabetes. No participant felt messages were too frequent. They enjoyed the portability and ability to learn information they "would not seek out in a book or on a computer." Self-reported changes of AADE behaviors that affect $\mathrm{A} 1 \mathrm{C}$ and self-management are listed in Figure 1.

Self-management behaviors are complex and interdependent. Perhaps the combination of messages irrespective of content served as cues to action to engage in self-care behaviors, as patient exit comments included "The messages were frequent reminders to be active in controlling my diabetes" and "Patients still have to take responsibility."

\section{Conclusions}

Vulnerable populations use text messaging at much higher rates than they use the Internet. ${ }^{18-21}$ Their ability to receive information and cues improves the possibility of engagement in self-management behaviors and improved outcomes. A TMP meets the IOM definition of high-quality care and is consis- tent with the comprehensive care delivered in a PCMH. Furthermore, a TMP crosses socioeconomic, ethnic, and gender boundaries and permits patients with expensive copays or who do not use the Internet to receive and store portable health information to which they can later refer. Broader and multilingual studies of TMPs are warranted as a population health tool to impact chronic disease and reduce disparities in care.

\section{Author Disclosure Statement}

No competing financial interests exist.

\section{References}

1. Artiga S, Young K, Garfield R, et al. Racial and ethnic disparities in access to and utilization of care among insured adults. Kaiser Family Foundation. 2015. Available at http://kff.org/report-section/racialand-ethnic-disparities-in-access-to-and-utilization-of-care-amonginsured-adults-issue-brief/ Accessed August 18, 2016.

2. American Diabetes Association. Statistics about diabetes. 2016. Available at www.diabetes.org/diabetes-basics/statistics/ Accessed August 20, 2016.

3. National Committee for Quality Assurance. The state of health care quality. 2015. Available at www.ncqa.org/report-cards/health-plans/ state-of-health-care-quality/2015-table-of-contents/diabetes-care Accessed August 20, 2016

4. American Diabetes Association. Standards of medical care in diabetes2016. Diabetes Care. 2016;39:S1:1-119.

5. United States Department of Health and Human Services. Promoting maternal and child health through text messaging. An evaluation of the Text4baby program-Final report. Rockville, MD, 2015.

6. American Association of Diabetes Educators: 7 Self-care behaviors 2010. Available at https://www.diabeteseducator.org/patient-resources/aade7self-care-behaviors Accessed March 10, 2014.

7. Cole-Lewis $\mathrm{H}$, Kershaw T. Text messaging as a tool for behavior change in disease prevention and management. Epidemiol Rev. 2010; 32:56-59.

8. Broderick A, Haque F. Mobile health and patient engagement in the safety-net: a survey of community health centers and clinics. The Commonwealth Fund. 2015. Available at www.commonwealthfund.org/ publications/issue-briefs/2015/may/mobile-health-and-patientengagement-in-the-safety-net Accessed August 18, 2016.

9. Bay SL, Crawford DJ. Using technology to affect influenza vaccine coverage among children with chronic respiratory conditions. J Pediatr Health Care. 2016 [Epub ahead of print]; DOI: 10.1016/ j.pedhc.2016.06.007.

10. Lopez $L$, Resser $L$, Rodriguez $N$, et al. Leveraging mobile technology to increase breastfeeding rates in Los Angeles County. Abstract. Obstet Gynecol. 2016;127:S1:23

11. Stephens JD, Yager AM, Allen J. Smartphone technology and text messaging for weight loss in young adults: A randomized controlled trial. J Cardiovasc Nurs. 2015 [Epub ahead of print]; DOI: 10.1097/JCN.00000000 00000307.

12. Mendoza-Vasconez AM, Linke S, Muñoz M. Promoting physical activity among underserved populations. Curr Sports Med Rep. 2016;15:4: 290-298.

13. Arts J, English C, Greene GW, et al. A nutrition intervention to increase whole grain intake in college students. Top Clin Nutr. 2016;31: 222-231.

14. Conserve DF, Jennings $L$, Aguia $C$, et al. Systematic review of mobile health behavioural interventions to improve uptake of HIV testing for vulnerable and key populations. J Telemed Telecare. 2016 [Epub ahead of print]. DOI: $10.1177 / 1357633 \times 16639186$

15. Dzubaty DR. Supporting neonatal intensive care unit parents through social media. J Perinat Neonatal Nurs. 2016;30:214-217. 
16. American College of Physicians. Living with Diabetes: An Everyday Guide for You and Your Family. Philadelphia, PA: American College of Physicians Foundation, 2006.

17. Ryan J, Jennings T, Vittoria I, et al. Short and long term outcomes from a multi-session diabetes education program targeting lowincome minority patients: a six month follow-up. Clin Ther. 2013;35: A43-A53.

18. Anderson M. Racial and ethnic differences in how people use mobile technology. Pew Research Center. 2015. Available at www.pewresearch .org/fact-tank/2015/04/30/racial-and-ethnic-differences-in-how-peopleuse-mobile-technology/ Accessed August 18, 2016.

19. Anderson M. Technology device ownership: 2015. Pew Research Center. 2015. Available at www.pewinternet.org/2015/10/29/technology-deviceownership-2015 Accessed August 18, 2016.

20. Smith A. US smartphone use in 2015. Pew Research Center. 2015. Available at www.pewinternet.org/2015/04/01/us-smartphone-use-in-2015/ Accessed August 18, 2016.

21. Rainie L, Zickuhr K. Americans' views on mobile etiquette. Pew Research Center. 2015. Available at www.pewinternet.org/2015/08/26/americansviews-on-mobile-etiquette/ Accessed August 18, 2016.
Cite this article as: Miller JM, Phalen AG, Crawford A, Frisby A, Ziring BS (2017) Text messaging in the patient-centered medical home to improve glucose control and retinopathy screening, Health Equity 1:1, 2-6, DOI: 10.1089/heq.2016.0003.

$\begin{aligned} & \text { Abbreviations Used } \\ & \mathrm{AADE}=\text { American Association of Diabetes Educators } \\ & \mathrm{ADA}=\text { American Diabetes Association } \\ & \mathrm{EMR}=\text { Electronic Medical Record } \\ & \mathrm{IOM}=\text { Institute of Medicine } \\ & \mathrm{NCQA}=\text { National Committee on Quality Assurance } \\ & \mathrm{PCMH}=\text { patient-centered medical home } \\ & \mathrm{RS}=\text { retinopathy screening } \\ & \mathrm{T} 2 \mathrm{DM}=\text { type } 2 \text { diabetes } \\ & \mathrm{TMP}=\text { text messaging program }\end{aligned}$

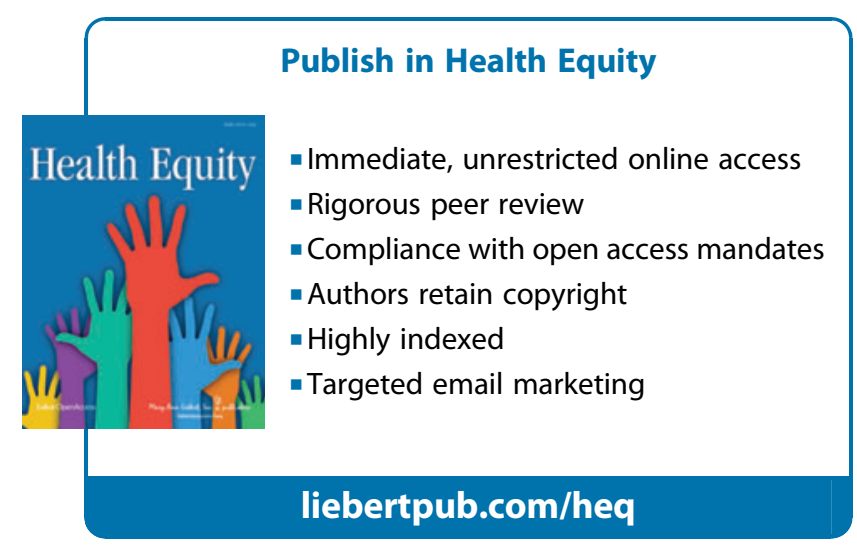

